\title{
Mandatory tuberculosis case notification in high tuberculosis-incidence countries: policy and practice
}

\author{
Mukund Uplekar ${ }^{1}$, Sachin Atre ${ }^{2}$, William A. Wells ${ }^{3}$, Diana Weil ${ }^{1}$, Rafael Lopez $^{4}$, \\ Giovanni Battista Migliori $\mathbb{1}^{5}$ and Mario Raviglione ${ }^{1}$
}

Affiliations:

${ }^{1}$ Global TB Programme, World Health Organization, Geneva, Switzerland.

${ }^{2} J o h n s$ Hopkins Clinical Trials Unit, BJ Medical College, Pune, India.

${ }^{3}$ US Agency for International Development, Washington, DC, USA.

${ }^{4}$ World Health Organization Regional Office for Americas, Washington DC, USA.

${ }^{5}$ Fondazione S. Maugeri Care and Research Institute, Tradate, Italy.

\section{Correspondence:}

Mukund Uplekar, Global TB Programme, World Health Organization, Avenue Appia, Geneva 1211, Switzerland. E-mail: uplekarmawho.int

ABSTRACT Mandatory tuberculosis (TB) notification is an important policy under the End TB Strategy, but little is known about its enforcement especially in high TB incidence countries. We undertook a literature search for selected high-incidence countries, followed by a questionnaire-based survey among key informants in countries with high-, intermediate- and low-TB incidence. Published literature on TB notification in high-incidence countries was limited, but it did illustrate some of the current barriers to notification and the importance of electronic systems to facilitate reporting by private providers. Required survey data were successfully gathered from 40 out of 54 countries contacted. TB is notifiable in 11 out of 15 high-incidence countries, all 16 intermediate-incidence countries, and all nine low-incidence countries contacted. TB case notification by public sector facilities is generally systematised, but few high-incidence countries had systems and tools to facilitate notification from private care providers. In the context of the new End TB Strategy aimed at eventual TB elimination, all countries should have TB on their national list of notifiable diseases. Enhancing the ease of notification by private providers is essential for effective implementation. To that effect, investing in strengthening disease surveillance systems and introducing digital tools to simplify notification are logical ways forward.

@ERSpublications

Mandatory case notification weak in high TB-burden countries; requires simple tools for private providers http://ow.ly/wZ9Z303bidB

Received: May 122016 | Accepted after revision: Aug 08 2016 | First published online: Oct 202016

This is one of a selection of articles published as ERJ Open papers, as part of an initiative agreed between the European Respiratory Society and the World Health Organization.

Support statement: Funding for this study was received from Eli Lily and Company Foundation. Funding information for this article has been deposited with Open Funder Registry.

Conflict of interest: Disclosures can be found alongside this article at erj.ersjournals.com

The content of this work is not subject to copyright. Design and branding are copyright @ERS 2016. This version is distributed under the terms of the Creative Commons Attribution Non-Commercial Licence 4.0. 


\section{Introduction}

Tuberculosis (TB) notification is defined as the process of reporting diagnosed TB cases to relevant health authorities, which in turn report them to the World Health Organization (WHO) through National TB Programmes (NTPs) or their equivalent. In 2014, 9.6 million people were estimated to develop active TB and 1.5 million died of TB [1]. However, only 6.3 million TB cases were notified. This leaves a gap of well over 3 million cases that are not notified. These are labelled as "missed" cases and the majority (75\%) of them belong to 12 high TB burden countries [2]. TB cases detected in the public sector health facilities generally get notified through routine reporting systems. However, a large proportion of cases that are detected and treated in the private sector do not get notified in many settings. Under-notification remains a major issue especially in countries with high incidence and a large private sector [3].

Ending the TB epidemic by 2030 is a globally accepted target under the Sustainable Development Goals, and WHO's End TB Strategy shows the way forward [4]. Integrated, patient-centred care and prevention, bold policies and supportive systems, and intensified research and innovation constitute the three pillars of the End TB Strategy. Mandatory TB case notification is highlighted as an integral element of overall regulatory frameworks essential for effective implementation of the strategy. WHO's framework for TB elimination in low-incidence countries also underscores the importance of mandatory case notification as a part of continuous surveillance and monitoring [5,6]. Furthermore, notification of all diagnosed TB cases to relevant health authorities is a standard of care incorporated in both international and European standards of TB care $[7,8]$.

TB case-notification policies and practices are well established in low-incidence countries [9], and mandatory notification is often recommended as a policy or practice in programme reviews in high-incidence countries. However, there is little documentation available from high-incidence countries on either the status of these policies or the issues and challenges with implementing them. Understanding the current situation would be a first step to identifying opportunities and ways to make mandatory TB case notification operational in all settings. The resulting improvements in notifications would help in understanding the precise disease burden and its distribution, thus allowing resources to be focused where they are most needed. Notification also provides an entry point for engaging private-care providers in delivering higher-quality TB care.

The present study was undertaken to: a) review the literature on mandatory TB case-notification policies and practices in high TB-incidence countries; b) document TB case-notification policies and practices in selected high, intermediate and low TB incidence countries; and c) identify issues and interventions to improve implementation of mandatory TB case notification in high incidence countries.

\section{Methods}

The study was based on a rapid assessment using mixed methods, which included a literature search for relevant documentation from selected countries and a questionnaire survey of key informants.

\section{Selection of countries}

High TB incidence countries were the main target of this study. However, intermediate- and low-incidence countries were also included in the survey process to gather lessons that may be applicable as high TB incidence countries intensify their efforts.

Currently, there are no globally accepted definitions for categorising countries according to levels of TB incidence. For the purposes of this study, we categorised countries as high, intermediate and low incidence if they had an incidence of $>70,20-69$, or $<20$ TB cases per 100000 population per year, respectively. This yielded 88, 49 and 68 countries in the high-, intermediate- and low-incidence categories, respectively. After ensuring sufficient sampling of all three categories, countries were chosen purposively depending on the availability of key informants to collect and provide required information for the surveys. The resulting list included 22 out of the 88 high-incidence countries, 19 out of the 49 intermediate-incidence countries, and 13 out of the 68 low-incidence countries. Based on disease burden and key informant availability, all except one of the intermediate incidence countries included in the study were from the Americas.

\section{Literature review}

In line with the focus of the study, the literature review was restricted to the 22 selected high-incidence countries, which later received survey instruments. We conducted a Medline search for English language articles published until July 2015 using combinations of broad terms such as "tuberculosis", "notification", the name of the selected high-incidence country and text terms such as, "mandatory" and "law". This search was later extended up to April 2016. Table 1 lists the 22 high-incidence countries for which the search was conducted. We also searched government websites for TB programmes in the selected countries for relevant published material. For additional grey literature, such as technical reports and working papers, we searched Google and Google Scholar web sites using the key words "mandatory", "TB”, 
TABLE 1 Medline search on mandatory TB notification in selected high-TB incidence countries

\begin{tabular}{lcc} 
Countries & Retrieved articles & Relevant articles \\
\hline Bangladesh & 23 & 0 \\
Belarus & 3 & 0 \\
Bolivia & 1 & 0 \\
Cambodia & 11 & 0 \\
China & 62 & {$[10,11]$} \\
Ethiopia & 14 & 0 \\
Guyana & 2 & 0 \\
Haiti & 0 & 0 \\
India & 80 & {$[12-20]$} \\
Indonesia & 10 & 0 \\
Kenya & 12 & 0 \\
Myanmar & 4 & 0 \\
Nigeria & 8 & 0 \\
Pakistan & 35 & 0 \\
Peru & 4 & 0 \\
The Philippines & 13 & 0 \\
Republic of Korea & 7 & {$[21-23]$} \\
South Africa & 83 & 0 \\
Tanzania & 9 & 0 \\
Thailand & 9 & 0 \\
Uganda & 9 & 0 \\
Vietnam & 29 & 0 \\
Total & 428 & 14 \\
\end{tabular}

"notification" and the name of each selected country. The literature review also helped identify areas of inquiry for the survey questionnaire.

\section{Self-completed questionnaires and document collection}

Following the literature review, a questionnaire-based survey was conducted among key informants that included relevant staff from WHO country offices, NTP managers, TB surveillance focal points, and partners associated with the Working Group on Public-Private Mix (PPM) for TB care. The WHO staff helped identify key informants and obtained available information. The questionnaire inquired about the existence of a mandatory TB notification policy and its enforcement, existing TB notification systems (manual, electronic or both), types of cases for which notification is required, time limit for notification, the agency responsible for enforcing notification, any penal provisions for non-reporting, challenges encountered, and successes in implementation. We filled any gaps in the information through additional email correspondence. Respondents were also requested to provide relevant grey literature and scanned copies of notification formats from selected countries.

\section{Data analysis}

Articles retrieved through the Medline search were examined for their relevance to mandatory TB case notification. Full texts of the relevant articles were downloaded and reviewed. The data collected through the survey was further analysed with reference to the questionnaire themes listed above. The results were tabulated and summarised using MS-Excel separately for high incidence, intermediate incidence and low incidence countries. Data were then thematically analysed to examine country-specific and cross-cutting issues related to mandatory TB notification policies and practices.

\section{Results}

Findings from the literature review

The Medline search retrieved 428 articles from the 22 high-incidence countries (table 1). Many of the retrieved articles were related to epidemiological studies, regional experiences or studies on PPM initiatives for TB control, with little information on mandatory TB notification. Retrieved articles were mainly for three countries: China [10, 11]; India [12-20]; and Republic of Korea [21-23]. The search yielded 14 articles relevant to the present study. Relevant grey literature was available for five countries that included Bangladesh, Pakistan, the Philippines, Thailand and Vietnam. These documents provided useful insights mainly into provider perceptions, including barriers to notification, and innovations enabled by the application of digital technology. These findings are outlined below. 
Rationale and justification for mandatory notification

A number of papers from India were prompted by the discussions and then enactment of mandatory notification in that country. It was noted that there are many target audiences for mandatory notification [15], that it would require a web-based system, punitive measures, monitoring and advocacy to be successful [13], and that compulsory notification would bring many opportunities for better resource management and outcomes [17]. A cautionary paper noted that notification is only justified if it prompts action, including on improving the quality of private sector TB care [14].

\section{Provider perceptions and barriers}

In Kerala, India, private providers assumed that only patients receiving nationally recommended treatment regimens needed to be notified. Private providers had concerns about the workload involved in notification procedures, breaching patient confidentiality about a stigmatising disease, non-supportive public sector staff and the absence of incentives [12]. In the Republic of Korea, lower notification was associated with providers who did not send patients for sputum smear and who prescribed fewer than four drugs, suggesting that generally low knowledge due to insufficient engagement on TB was a likely barrier to notification [23]. A study from Pakistan reported that private practitioners were doubtful about the feasibility and utility of imposing fines to improve disease notification; they noted a lack of time as the major reason for not reporting, followed by confidentiality and poor knowledge of the reporting procedure [24]. Similarly, in two studies in India, the main reasons for not notifying included lack of time, confidentiality concerns, fear of offending patients, lack of knowledge about notification, no simple notification mechanism, and lack of trust and coordination with government $[12,19]$. In Nigeria, many providers were unaware of notification requirements [25].

\section{Digital tools and innovations}

The literature review provided insights into recent advances in internet-based disease surveillance systems. Providers in India preferred to notify through mobile phones, SMS or email [20]. A number of papers described the establishment of electronic recording and reporting systems in China $[10,11]$ and Korea [22, 23], including interoperability with a general infectious disease reporting system [11], the ability to improve referrals using these systems [10], and the analysis of health insurance data to get at the true burden of disease [23].

\section{Findings from the survey and country-specific documentation}

Required survey data were successfully gathered from 40 countries including 15 out of 22 high-incidence countries, 16 out of 19 intermediate-incidence countries and nine out of 13 low-incidence countries. Scanned copies of case notification formats were received from five countries. Tables 2, 3 and 4 present summaries of survey findings from high-, intermediate- and low-incidence countries, respectively.

\section{$T B$ in the list of notifiable diseases}

Currently, TB is not notifiable in four of the 15 high-incidence countries surveyed. No movement to mandatory notification was reported for Myanmar. However, measures to rectify this situation are being taken in the other three high-incidence countries that do not yet mandate notification. In Pakistan, which has a federal structure, one province has recently approved a bill on mandatory TB case notification. In the Philippines, national legislation on TB which incorporates mandatory TB case notification was passed in April 2016. In Indonesia, the process of including TB in the revised list of notifiable diseases is underway. Of note, in Bangladesh, TB has been declared notifiable and thus is marked as a "yes" in table 2, but operational guidelines for its enforcement are yet to be prepared.

In all but two countries that mandate notification, notification of all forms of $\mathrm{TB}$ is required (the exceptions are China and Guatemala, which mandate notification only of pulmonary or smear positive $\mathrm{TB}$, respectively). In five low-incidence countries and one high-incidence country, suspected TB cases (meaning a clinically diagnosed case in these settings) are also expected to be notified in addition to bacteriologically confirmed TB cases.

Formats for case notification

TB case notification formats vary from country to country. Some countries have separate notification formats for medical practitioners, clinics, hospitals and laboratories. Some formats are compact while others are comprehensive. Variables commonly included in the formats are: details of the health facility; patient's general information such as name, age, sex, identification number, address and telephone number; and dates of diagnosis and treatment initiation. Additional fields that are present more variably include immigration status, occupation, history of prior treatment, bacille Calmette-Guérin vaccination status, anatomical site of the disease and International Classification of Diseases (ICD) 10 classification, 


\begin{tabular}{|c|c|c|c|c|c|c|c|}
\hline Country & $\begin{array}{l}2013 \text { TB incidence } \\
\text { rate per } 100000 \\
\text { population }\end{array}$ & $\begin{array}{l}\text { Mandatory TB } \\
\text { case notification } \\
\text { by all providers }\end{array}$ & $\begin{array}{l}\text { Notification } \\
\text { system }\end{array}$ & $\begin{array}{l}\text { Type of cases for } \\
\text { which notification } \\
\text { is required }\end{array}$ & $\begin{array}{l}\text { Time limit for } \\
\text { notification }\end{array}$ & $\begin{array}{c}\text { Agency responsible for } \\
\text { enforcing mandatory } \\
\text { notification }\end{array}$ & $\begin{array}{l}\text { Penal provisions } \\
\text { if fail to notify }\end{array}$ \\
\hline Bangladesh & 224 & Yes & M & All diagnosed TB & Unclear & NTP & None \\
\hline Belarus & 70 & Yes & $M+E$ & All diagnosed TB & Unclear & $\mathrm{NTP} /(\mathrm{MoH})$ & $\begin{array}{l}\text { Legal action is only in public } \\
\text { sector, as there is no } \\
\text { TB treatment in private sector }\end{array}$ \\
\hline Bolivia & 123 & Yes & M & All diagnosed TB & Within a week & Agency outside $\mathrm{MoH}$ & None \\
\hline China & 70 & Yes & $E$ & $\begin{array}{l}\text { Only pulmonary TB and } \\
\text { presumptive TB }\end{array}$ & Within $24 \mathrm{~h}$ & CDC, China & Unclear \\
\hline Ethiopia & 224 & Yes & $M+E$ & All diagnosed TB & Quarterly & NTP & None \\
\hline Haiti & 206 & Yes & M & All diagnosed TB & Unclear & NTP/MoH & None \\
\hline India & 171 & Yes & $M+E$ & All diagnosed TB & Monthly & RNTCP/MoH & $\begin{array}{l}\text { Recommended } \\
\text { punitive action }\end{array}$ \\
\hline Indonesia & 183 & No & $M+E$ & NA & NA & NA & NA \\
\hline Myanmar & 373 & No & M & NA & NA & NA & NA \\
\hline Pakistan & 275 & No & $M+E$ & NA & NA & $\begin{array}{l}\text { NA, in future- district } \\
\text { health authority }\end{array}$ & $\begin{array}{l}\text { NA at national level, though } \\
\text { imprisonment up to } 2 \text { years or } \\
\text { fine up to } 500000 \text { Rupees or } \\
\text { both, for Sindh province only }\end{array}$ \\
\hline Peru & 124 & Yes & $M+E$ & All diagnosed TB & Within a week & $\begin{array}{l}\text { Dept. of Epidemiology/ } \\
\mathrm{MoH}\end{array}$ & None \\
\hline The Philippines & 292 & No & $M$ & NA & NA & NA & NA \\
\hline Republic of Korea & 97 & Yes & $M+E$ & All diagnosed TB & Within a week & CDC, Korea & Provision of fine: $\$ 2000$ \\
\hline Thailand & 119 & Yes & $M+E$ & All diagnosed TB & Unclear & Dept of disease control & Provision of fine: 2000 Baht \\
\hline Vietnam & 144 & Yes & $M+E$ & All diagnosed TB & Quarterly & NTP/MoH & None \\
\hline
\end{tabular}

M: manual; E: electronic; M+E: partly manual and partly electronic; NTP: National TB Programme; MoH: Ministry of Health; CDC: Centers for Disease Control and Prevention; NA: not applicable. 
TABLE 3 Summary of status of mandatory case notification in intermediate tuberculosis (TB) incidence countries as of December 2014

\begin{tabular}{|c|c|c|c|c|c|c|c|}
\hline Country & $\begin{array}{l}2013 \text { TB incidence } \\
\text { rate per } 100000 \\
\text { population }\end{array}$ & $\begin{array}{l}\text { Mandatory } \\
\text { TB case } \\
\text { notification }\end{array}$ & $\begin{array}{l}\text { Notification } \\
\text { system }\end{array}$ & $\begin{array}{l}\text { Type of cases for } \\
\text { which notification } \\
\text { is required }\end{array}$ & $\begin{array}{l}\text { Time limit for } \\
\text { notification }\end{array}$ & $\begin{array}{l}\text { Agency responsible for } \\
\text { enforcing mandatory } \\
\text { notification }\end{array}$ & $\begin{array}{l}\text { Penal provisions } \\
\text { if fail to notify }\end{array}$ \\
\hline Argentina & 24 & Yes & E & All diagnosed TB & Unclear & $\mathrm{DoE} / \mathrm{MoH}$ & None \\
\hline Belize & 37 & Yes & $M+E$ & All diagnosed TB & Unclear & $\mathrm{DoE} / \mathrm{MoH}$ & None \\
\hline Brazil & 46 & Yes & $E$ & All diagnosed TB & Unclear & $\mathrm{DoE} / \mathrm{MoH}$ & $\begin{array}{l}\text { Closure of facility, } \\
\text { penalty, Imprisonment }\end{array}$ \\
\hline Colombia & 32 & Yes & E & All diagnosed TB & Within a week & $\mathrm{DoE} / \mathrm{MoH}$ & Warning call \\
\hline Dominican Republic & 60 & Yes & $\mathrm{M}+\mathrm{E}$ & All diagnosed TB & Within a week & $\mathrm{DoE} / \mathrm{MoH}$ & Imprisonment \\
\hline Ecuador & 56 & Yes & $M+E$ & All diagnosed TB & Unclear & Unclear & Unclear \\
\hline El Salvador & 39 & Yes & $M+E$ & All diagnosed TB & Within a week & $\mathrm{DoE} / \mathrm{MoH}$ & $\begin{array}{l}\text { Closure of facility, } \\
\text { penalty, Imprisonment }\end{array}$ \\
\hline Guatemala & 60 & Yes & $M+E$ & $\begin{array}{c}\text { Only smear positive } \\
\text { TB }\end{array}$ & Unclear & $\mathrm{DoE} / \mathrm{MoH}$ & None \\
\hline Honduras & 54 & Yes & M & All diagnosed TB & Unclear & NTP/MoH & None \\
\hline Nicaragua & 55 & Yes & $M+E$ & All diagnosed TB & Unclear & $\mathrm{DoE} / \mathrm{MoH}$ & None \\
\hline Panama & 48 & Yes & $E$ & All diagnosed TB & Unclear & $\mathrm{DoE} / \mathrm{MoH}$ & Penalty, imprisonment \\
\hline Paraguay & 44 & Yes & $M+E$ & All diagnosed TB & Unclear & NTP/MoH & None \\
\hline Sri Lanka & 66 & Yes & M & All diagnosed TB & Within a week & $\mathrm{NTP} / \mathrm{MoH}$ & $\begin{array}{l}\text { None (No TB cases in } \\
\text { the private sector) }\end{array}$ \\
\hline St. Vincent and the Grenadines & 24 & Yes & M & All diagnosed TB & Unclear & $\mathrm{DoE} / \mathrm{MoH}$ & None \\
\hline Uruguay & 30 & Yes & $M+E$ & All diagnosed TB & Within a week & $\mathrm{DoE} / \mathrm{MoH}$ & None \\
\hline Venezuela & 33 & Yes & $M+E$ & All diagnosed TB & Unclear & $\mathrm{DoE} / \mathrm{MoH}$ & $\begin{array}{l}\text { Visit by ministry } \\
\text { officials, closure of } \\
\text { facility }\end{array}$ \\
\hline
\end{tabular}


TABLE 4 Summary of status of mandatory case notification in selected low TB-incidence countries as of December 2014

\begin{tabular}{|c|c|c|c|c|c|c|c|}
\hline Country & $\begin{array}{l}2013 \text { TB incidence } \\
\text { rate per } 100000 \\
\text { population }\end{array}$ & $\begin{array}{l}\text { Mandatory TB case } \\
\text { notification by all } \\
\text { providers }\end{array}$ & $\begin{array}{l}\text { Notification } \\
\text { system }\end{array}$ & $\begin{array}{l}\text { Type of cases for } \\
\text { which notification } \\
\text { is required }\end{array}$ & $\begin{array}{l}\text { Time limit for } \\
\text { notification }\end{array}$ & $\begin{array}{l}\text { Agency responsible for } \\
\text { enforcing mandatory } \\
\text { notification }\end{array}$ & $\begin{array}{l}\text { Penal provisions } \\
\text { if fail to notify }\end{array}$ \\
\hline Bahamas & 10 & Yes & M & All diagnosed TB cases & Unclear & $\mathrm{NTP} / \mathrm{MoH}$ & Penalty \\
\hline Canada & 5 & Yes & $M+E$ & $\begin{array}{c}\text { All diagnosed TB cases } \\
\text { and suspects }\end{array}$ & Within $48 \mathrm{~h}$ & $\mathrm{DoE} / \mathrm{MoH}$ & $\begin{array}{l}\text { Closure of facilities, } \\
\text { fine }(\$ 600 \text { or } \$ 1200) \text { for the } \\
\text { first offence, double for the } \\
\text { next, possible imprisonment }\end{array}$ \\
\hline Costa Rica & 11 & Yes & $M+E$ & All diagnosed TB cases & Unclear & $\mathrm{DoE} / \mathrm{MoH}$ & $\begin{array}{l}\text { Warning call, } \\
\text { no specific penalty }\end{array}$ \\
\hline Cuba & 9 & Yes & M & All diagnosed TB cases & Within a week & $\mathrm{DoE} / \mathrm{MoH}$ & Unclear \\
\hline Grenada & 4 & Yes & M & $\begin{array}{c}\text { All diagnosed TB cases } \\
\text { except MDR-TB and } \\
\text { age }<15 \text { years }\end{array}$ & Unclear & $\mathrm{DoE} / \mathrm{MoH}$ & None \\
\hline Italy & 6 & Yes & $M+E$ & $\begin{array}{c}\text { All diagnosed TB cases } \\
\text { and suspects }\end{array}$ & Within $48 \mathrm{~h}$ & $\begin{array}{l}\text { Local public health } \\
\text { units }\end{array}$ & $\begin{array}{l}\text { Administrative fees } \\
\text { and detention }\end{array}$ \\
\hline The Netherlands & 6 & Yes & $\mathrm{E}$ & $\begin{array}{c}\text { All diagnosed TB cases } \\
\text { and suspects }\end{array}$ & Within $24 \mathrm{~h}$ & $\begin{array}{c}\text { Municipal Public Health } \\
\text { Service }\end{array}$ & $\begin{array}{l}\text { Detention for maximum } \\
2 \text { months or fine, } \\
\text { no information on } \\
\text { execution of this. }\end{array}$ \\
\hline UK & 13 & Yes & $M+E$ & $\begin{array}{c}\text { All diagnosed } \\
\text { TB cases and suspects }\end{array}$ & $\begin{array}{c}\text { Within } \\
3 \text { working days }\end{array}$ & $\begin{array}{l}\text { Health Protection } \\
\text { Agency, Department } \\
\text { of Health }\end{array}$ & $\begin{array}{c}\text { No offence in the Notification } \\
\text { Regulations because there are } \\
\text { other mechanisms for dealing } \\
\text { with non-compliance with legal } \\
\text { requirements }\end{array}$ \\
\hline USA & 3 & Yes & $M+E$ & $\begin{array}{c}\text { All diagnosed TB cases } \\
\text { and suspects }\end{array}$ & Within a week & $\mathrm{DoE} / \mathrm{MoH}$ & $\begin{array}{c}\text { Closure of facilities, fine, } \\
\text { imprisonment }\end{array}$ \\
\hline
\end{tabular}


clinical summary, diagnostic criteria, information on index case (if the patient was found based on being a contact), treatment history, and treatment outcome.

Of the five countries (three high incidence and two low incidence) from where notifications formats were available, only one, the Republic of Korea, has treatment outcome included. In the Republic of Korea, an electronic system allows reporting on both the notification and treatment outcome.

\section{Enforcement agencies and reporting requirements}

Key informants noted that there was minimal staffing available for enforcement of mandatory notification in high TB incidence countries, which suggest that it is left to voluntary compliance on the part of care providers. Among most low- and intermediate-incidence countries, departments of epidemiology within the ministries of health were reported as the agency responsible for enforcement. Other country-specific responsible agencies included the NTP, local public health units, municipal public health services and the health protection agency.

Information on the time-limit for notification of TB cases was available from 18 countries. In China, notification should be done within $24 \mathrm{~h}$ of diagnosis. The time limits elsewhere were 1 week to 3 months in the other six high TB incidence countries, a week in five intermediate TB incidence countries and two low TB incidence countries, and 1-3 days in four other low TB incidence countries.

\section{Penal provisions}

For 10 high TB incidence countries, the policy on penal provisions for failure to notify was clear. Of these, five have no penal provisions for failure to notify; out of the remaining five, three countries have a provision for imposing fines but it is rarely practiced. It involves a heavy financial penalty with possible imprisonment in one high-incidence setting. Incremental penal provisions among intermediate and low TB incidence countries included warning calls, administrative fines, closure of the facility, and imprisonment.

\section{Operational constraints}

Some commonly reported constraints for implementing mandatory TB notification in high TB incidence countries included obtaining funds for the basic infrastructure and maintenance of electronic notification systems, staff turnover and continuing education of concerned staff, getting responsible staff to trace notified patients, training and monitoring of private sector providers, cumbersome paper-based systems and addressing delays in notification.

\section{Discussion}

Notification of cases of infectious diseases has been and remains a critical step in controlling and preventing the spread of communicable diseases. With TB being a leading infectious cause of disease and death globally, notification of TB cases is particularly important. Notification is essential for routine surveillance and for determining the burden of TB in a community or country, it is useful to detect the source of infection and outbreaks, it helps establish appropriateness of diagnosis and provision of recommended treatment, and it is essential for planning, implementing and evaluating care and prevention programmes. TB case notification is absolutely necessary in countries nearing pre-elimination and elimination.

Under-notification of TB cases remains a serious and persistent global problem that impedes a correct understanding of the burden of disease and of the impact of the response. It is also a reflection of weak general public health surveillance. WHO's new End TB Strategy underscores the need to strengthen public health regulatory frameworks including mandatory $\mathrm{TB}$ case notification. This study is the first one to provide an overview of policy and practice of mandatory TB case notification in high TB-incidence settings.

This assessment has some inherent limitations: proper geographical representation could not be ensured and further probing of absent, unclear or incomplete responses could not be undertaken. However, it provides useful information on the topic and establishes a foundation for further systematic investigations. These future investigations could include more in-depth topics such as notification from laboratories, notification of not just diagnosis but also outcomes, balancing the competing desires for detailed information but simple notification formats, and notification of cases detected using new, molecular diagnostics as well as through active case finding.

Only a few high TB incidence countries do not have TB included in the list of notifiable diseases. We did not measure the extent of compliance of care providers with these mandatory notification laws and regulations, but it is clear from the global and country notification gaps described earlier that compliance with mandatory notification is very limited in high TB-incidence settings. Clearly, making TB notification 
mandatory is an essential starting point but not sufficient to ensure that each TB case detected gets notified to relevant health authorities.

Enforcing policies requires far greater efforts than enacting them [27]. TB case notification from public sector health facilities, especially those not linked to the NTP, may be further improved. However, the greatest contributor to under-notification is still likely to be the incomplete compliance of private providers with existing mandatory notification laws. This is often driven by a failure to rollout a notification system that is simple enough for an average private provider to put into routine practice, and the failure of governments to fund agencies that support private providers in TB activities. Such agencies are critical to strengthen the public health functions of adherence and reporting, which individual private providers will typically be poorly placed to carry out [3].

Our literature review uncovered many independent reports of providers struggling in the absence of simple notification systems, and a number of papers on promising electronic notification systems. Indeed, a number of high-incidence countries either have or are transitioning to electronic systems for recording and reporting TB data, and WHO promotes and supports these efforts [28]. In combination with simple, user-friendly input mechanisms for private providers, this transition seems the most likely pathway to significantly increase notification from both public and private sectors. This will require substantial inputs in terms of policies, financial and human resources, and orientation and training.

Electronic reporting can help overcome other barriers. Providers' confidentiality concerns can be alleviated by using codes assigned to TB cases rather than personal identifiers [9], which may be easier to handle with electronic systems. And electronic systems can also move countries towards real-time reporting. Long-standing guidance from WHO has promoted real-time recording at the facility level but only periodic reporting to higher levels (district and above). This reduces the likelihood of a real-time response. However, with electronic recording and reporting, real-time reporting and real-time responses become more practical [28], bringing further potential benefits from notifications which can now be tied to improved responses in real time.

The examples of China and India, the two countries with the highest TB burdens, are noteworthy. China has both a vertical (for TB) and an integrated electronic disease surveillance system. The combined and integrated use of these systems led to a doubling of case notifications between 2000 and 2009, with a major contribution from general public hospitals that were previously not directly linked to the TB programme [28]. India has a large private sector that provides treatment to approximately $50 \%$ of all $\mathrm{TB}$ patients [29]. Following the introduction of a policy of mandatory notification of TB cases in May 2012, India launched a new web-based TB surveillance system called NIKSHAY [30]. This system is accessible, via android-based smartphones and a web-portal, to both public and private health facilities, and requires entry of only eight mandatory data fields from private providers. By launching NIKSHAY and reaching out to the private sector, India achieved a 29\% increase in case notifications in 2014 compared with 2013 [2]. An even more dramatic increase of $47 \%$ in one year was seen in Taiwan after paying for notification and requiring notification as a condition for insurance reimbursement [31]; the result, several years later, was timely and substantially complete notification [32].

The problem of under-notification of TB cases in high-incidence countries should be viewed within the larger context of public health surveillance and infectious disease notification. In this regard, policies and practices in low-incidence countries may provide useful lessons. For example, a recent European survey showed that almost all countries surveyed had case-based electronic TB surveillance and over half (58\%) had dedicated TB surveillance staff for data validation and quality assurance activities. Importantly though, supportive supervision of programmatic activities, including case notifications, was being routinely undertaken in $61 \%$ of the countries [6].

For mandatory notification systems to be functional, several iterative actions are required (figure 1). First, a policy, mandating case notification, has to be in place. Countries should adopt a comprehensive approach to developing or updating TB surveillance, including elements needed to improve the quality of TB care and to track progress on targets for the new End TB Strategy. Second, systems and mechanisms to register all relevant providers and facilitate notification by them need to be developed and disseminated. These may include training tools, paper-based or electronic forms and details outlining the logistics of submission, collation and analysis of data gathered [33]. Third, all relevant healthcare providers need to be oriented about the policies and mechanisms. Ongoing monitoring should help check provider compliance. Finally, periodic reviews that also include provider feedback can help identify ways to make the system simpler and better, and also enhance and sustain cooperation of providers $[5,6]$.

Investing to modernise public health surveillance in general will have far-reaching benefits beyond operationalising mandatory TB case notification. As the examples of China and India illustrate, simplifying 


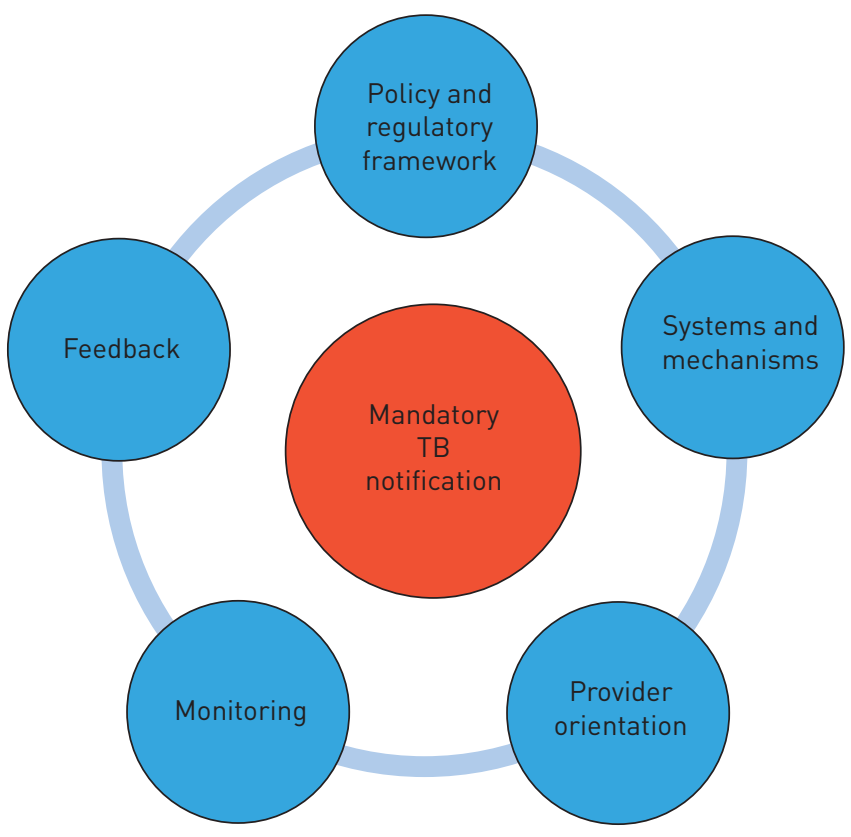

FIGURE 1 Iterative actions to implement mandatory tuberculosis (TB) case notification.

the process by making effective use of digital tools can enhance the efficiency of the system and improve compliance of both public and private providers. Ideally, this should be pursued as a part of the larger digital health agenda to help implement the End TB Strategy and progress towards TB elimination [34].

\section{Acknowledgements}

The authors gratefully acknowledge the managers of the National TB Programmes or equivalent entities in all the countries from where information was collected for this study. Special thanks are due to Jose Antonio Sulca for collecting and compiling data from countries in the Americas region which also involved translation of the questionnaire to Spanish. The contribution and support of the following to collecting and providing information from the countries are deeply appreciated: Ibrahim Abubakar, Sreenivas Achutan-Nair, Angel Alvarez, Denise Arakaki, Miguel Angel Aragón, Pedro Avedillo, Margarette Bury, Rosella Centis, Erwin Cooreman, Lia D’Ambrosio, Ingrid García, Mirtha Del Granado, Masoud Dara, Pierpaolo De Colombani, Gerard de Vrie, Celina Garfin, Antonio Hegar, Cornelia Hennig, Bin Hoa, Basharat Javed, Kathryn Johnston, Grace Park, Alina Perez, Enrique Perez, Soledad Perez, Khurshid Hyder, Akramul Islam, Daniel Kibuga, Andargachew Kumsa, Setiawan Jati Laksono, Woojin Lew, Roberto Montoya, Romeo Montoya, Janakan Navratnasigum, Suez Panama, Ejaz Qadeer, Valentin Rosovich, Roxana Salamanca, Roberto Salvatella, Thais dos Santos, Mukta Sharma, Aida Soto, Alfonso Tenorio, Jorge Victoria, Marcelo Vila and David Zavala. The review and comments on the draft manuscript by Hanna Monica Dias and Knut Lönnroth are thankfully acknowledged. MU, DW, RL, and MR are employed by the World Health Organization, and WAW is employed by the US Agency for International Development. The views and opinions expressed in this paper are those of the authors and not necessarily the views and opinions of their respective organisations.

\section{References}

1 World Health Organization. Global Tuberculosis Control Report 2015 (WHO/HTM/TB/2015.22). Geneva, World Health Organization, 2015.

2 World Health Organization. Global Tuberculosis Control Report 2014 (WHO/HTM/TB/2014.09). Geneva, World Health Organization, 2014.

3 Wells WA, Uplekar M, Pai M. Achieving systemic and scalable private sector engagement in tuberculosis care and prevention in Asia. PLoS Med 2015; 12: e1001842.

Uplekar M, Weil D, Lonnroth K, et al. WHO’s new End TB Strategy. Lancet 2015; 385: 1799-1801.

5 Lönnroth K, Migliori GB, Abubakar I, et al. Towards tuberculosis elimination: an action framework for low-incidence countries. Eur Respir J 2015; 45: 928-952.

6 D'Ambrosio L, Dara M, Tadolini M, et al. Tuberculosis elimination: theory and practice in Europe. Eur Respir J 2014; 43: 1410-1420.

7 Hopewell PC, Fair EL, Uplekar M. Updating the International Standards for Tuberculosis Care. Entering the era of molecular diagnostics. Ann Am Thorac Soc 2014; 11: 277-285.

8 Migliori GB, Zellweger JP, Abubakar I, et al. European Union standards for tuberculosis care. Eur Respir J 2012; 39: 807-819.

9 Mor Z, Migliori G, Althmsons S. Comparisons of tuberculosis surveillance systems in low incidence industrialized countries. Eur Respir J 2008; 32: 1616-1624.

10 Wang L, Liu X, Huang F, et al. Engaging hospitals to meet tuberculosis control targets in China: using the Internet as a tool to put policy into practice. Bull World Health Organ 2010; 88: 937-942.

11 Huang F, Cheng S, Du S, et al. Electronic recording and reporting system for tuberculosis in China: experience and opportunities. J Am Med Inform Assoc 2014; 21: 938-941. 
12 Philip S, Isaakidis P, Sagili KD, et al. "They Know, They Agree, but They Don't Do": the paradox of tuberculosis case notification by private practitioners in Alappuzha District, Kerala, India. PLoS One 2015; 10: e0123286.

13 Nagaraja S, Achanta S, Kumar A, et al. Extending tuberculosis notification to the private sector in India: programmatic challenges. Int J Tuber Lung Dis 18: 1353-1356.

14 Gawde N. Do we need notification of tuberculosis? A public health perspective. Indian J Med Ethics 2013; 10: 56-58.

15 Shrivastava S, Shrivastava S, Ramaswamy J. Notification of tuberculosis cases in India: moving ahead in the Revised National Tuberculosis Control Program. Infect Ecolo Epidemiol 2013; 3: 23006.

16 Bhaumik S, Biswas T. India makes tuberculosis a notifiable disease. Can Med Assoc J 2012; 184: E519-E520.

17 Roy S, Rai DR, Suresh G. Tuberculosis: a notifiable disease. J Indian Med Assoc 2012; 110: 728-731.

18 Velayutham B, Thomas B, Nair D, et al. The usefulness and feasibility of Mobile Interface in Tuberculosis Notification (MITUN) voice based system for notification of tuberculosis by private medical practitioners: a pilot project. PLoS One 2015; 10: e0138274.

19 Yeole RD, Khillare K, Chadha VK, et al. Tuberculosis case notification by private practitioners in Pune, India: how well are we doing? Public Health Action 2015; 5: 173.

20 Thomas BE, Velayutham B, Thiruvengadam K, et al. Perceptions of private medical practitioners on tuberculosis notification: A study from Chennai, South India. PLoS One 2016; 11: e0147579.

21 Hong S-J, Park Y-S, An H, et al. Factors leading to under-reporting of tuberculosis in the private sector in Korea. Int J Tuber Lung Dis 2012; 16: 1221-1227.

22 Lew W, Lee E, Bai J, et al. An Internet-based surveillance system for tuberculosis in Korea. Int J Tuber Lung Dis 2006; 10: 1241-1247.

23 Park Y-S, Hong S-J, Boo Y-K, et al. The national status of tuberculosis using nationwide medical records survey of patients with tuberculosis in Korea. Tuberc Respir Dis 2012; 73: 48-55.

24 Mansuri F, Borhany T, Kalar M. Factors responsible for underreporting of notifiable infectious diseases by general practitioners: a veiled reality. Biomedica 2014; 30: 126-129.

25 Adefuye BO, Diaro MD, Adedokun BO, et al. Knowledge, attitude and practice of infectious disease surveillance/ notification among doctors in a tertiary institution in Sagamu, Nigeria. Am J Respir Crit Care Med 2009; 179: A5197.

26 World Bank. TB incidence data Available from http://data.worldbank.org/indicator/SH.TBS.INCD. Date last accessed: December 24, 2015.

27 Doherty JE. Regulating the for-profit private health sector: lessons from East and Southern Africa. Health Policy Plan 2015; 30: suppl 1, i93-102.

28 World Health Organization. Electronic recording and reporting for tuberculosis care and control. (WHO/HTM/ TB/2011.22). Geneva, World Health Organization, 2012.

29 Wells WA, Ge CF, Patel N, et al. Size and usage patterns of private TB drug markets in the high burden countries. PLoS One 2011; 6: e18964.

30 Government of India. http://nikshay.gov.in/AboutNikshay.htm Date last accessed: April 7, 2016.

31 Chiang CY, Enarson DA, Yang SL, et al. The impact of national health insurance on the notification of tuberculosis in Taiwan. Int J Tuberc Lung Dis 2002; 6: 974-979.

32 Lo HY, Yang SL, Chou P, et al. Completeness and timeliness of tuberculosis notification in Taiwan. BMC Public Health 2011; 11: 915.

33 Falzon D, Raviglione $\mathrm{M}$, Bel EH, et al. The role of eHealth and mHealth in tuberculosis and tobacco control: a WHO/ERS consultation. Eur Respir J 2015; 46: 307-311.

34 World Health Organization. Digital health for the End TB Strategy - An agenda for action. (WHO/HTM/TB/ 2015.21). Geneva, World Health Organization, 2015. 